\title{
Erratum zu: Funktionelle Elektrostimulation in der Neurorehabilitation
}

T. Schick

\section{Erratum zu: (Hrsg.), Funktionelle Elektrostimulation in der Neurorehabilitation https://doi.org/10.1007/978-3-662-61705-2}

Beitrag von Thomas Schick: Funktionelle Elektrostimulation bei Störungen der Motorik aufgrund von Schädigung des Zentralen Nervensystems https://doi.org/10.1007/978-3-662-61705-2_6

Die DOIs der Abbildungen 6.3 (Seite 76), 6.4 (Seite 77), 6.5 (Seite 79) und 6.6 (Seite 80) wurden verlagsseitig falsch verlinkt und daher korrigiert. 